Article

\title{
Accelerating NMR-Based Structural Studies of Proteins by Combining Amino Acid Selective Unlabeling and Fast NMR Methods
}

\author{
Bankala Krishnarjuna ${ }^{1}$ (D), Kousik Chandra ${ }^{1, *}$ and Hanudatta S. Atreya ${ }^{1,2, *}$ \\ 1 NMR Research Centre, Indian Institute of Science, Bangalore 560012, India; krishnarjuna.bio@gmail.com \\ 2 Solid State and Structural Chemistry Unit, Indian Institute of Science, Bangalore 560012, India \\ * Correspondence: kousikc@iisc.ac.in (K.C.); hsatreya@iisc.ac.in (H.S.A.); \\ Tel.: +91-80-2293-3302 (K.C. \& H.S.A.); Fax: +91-80-2360-1550 (H.S.A.)
}

Received: 30 October 2017; Accepted: 7 December 2017; Published: 26 December 2017

\begin{abstract}
In recent years, there has been a growing interest in fast acquisition and analysis of nuclear magnetic resonance (NMR) spectroscopy data for high throughput protein structure determination. Towards this end, rapid data collection techniques and methods to simplify the NMR spectrum such as amino acid selective unlabeling have been proposed recently. Combining these two approaches can speed up further the structure determination process. Based on this idea, we present three new two-dimensional (2D) NMR experiments, which together provide ${ }^{15} \mathrm{~N},{ }^{1} \mathrm{HN},{ }^{13} \mathrm{C}^{\alpha},{ }^{13} \mathrm{C}^{\beta},{ }^{13} \mathrm{C}^{\prime}$ chemical shifts for amino acid residues which are immediate C-terminal neighbors $(i+1)$ of residues that are selectively unlabeled. These experiments have high sensitivity and can be acquired rapidly using the methodology of G-matrix Fourier transform (GFT) NMR spectroscopy combined with non-uniform sampling (NUS). This is a first study involving the application of fast NMR methods to proteins samples prepared using a specific labeling scheme. Taken together, this opens up new avenues to using the method of selective unlabeling for rapid resonance assignment of proteins.
\end{abstract}

Keywords: selective unlabeling; GFT NMR; non-uniform sampling; fast NMR methods; protein resonance assignments

\section{Introduction}

During the last decade, there has been a growing emphasis on speeding up the structure determination process of proteins by NMR spectroscopy, especially in the context of structural genomics projects, which require high throughput structure determination [1-4]. This is due to the fact that the conventional approaches for NMR data acquisition and analysis are time consuming. Typically, protein samples enriched uniformly with ${ }^{13} \mathrm{C}$ and / or ${ }^{15} \mathrm{~N}$ isotopes are prepared and a suite of 2D and 3D heteronuclear spectra are acquired for sequence specific resonance assignments [5]. With the conventional approach of data collection (e.g., linear sampling) this requires a few days to weeks of measurement time. Acquiring data in two different ways can accelerate this. One involves the rapid collection of multidimensional data using the recently proposed methods for fast data acquisition [1-4,6-9]. These methods reduce the time taken for data collection by an order of magnitude or more. The second approach involves augmenting the data acquired using uniformly ${ }^{13} \mathrm{C}$, ${ }^{15} \mathrm{~N}$ labeled protein sample with those acquired with selectively labeled/unlabeled samples [10-12]. Selective unlabeling or "reverse" labeling involves the ${ }^{13} \mathrm{C} /{ }^{15} \mathrm{~N}$ enrichment of all but specific chosen amino acids in a protein, which are rendered unlabeled $\left({ }^{12} \mathrm{C} /{ }^{14} \mathrm{~N}\right)[11,13-17]$. This helps in simplifying the NMR spectrum by reducing the number of peaks in the spectrum, and thereby, aiding unambiguous resonance assignments. 
We propose here a novel approach, which combines different methods for fast data acquisition with amino acid selective unlabeling to accelerate NMR data collection and analysis. Three new NMR experiments are proposed, two of which involve G-matrix Fourier transform (GFT) NMR spectroscopy $[18,19]$ applicable to a selectively unlabeled protein sample. The experiments together provide the chemical shifts of ${ }^{15} \mathrm{~N},{ }^{1} \mathrm{HN},{ }^{13} \mathrm{C}^{\alpha},{ }^{13} \mathrm{C}^{\beta},{ }^{13} \mathrm{C}^{\prime}$ nuclei of the C-terminal neighbor $\left({ }^{\prime} i+1^{\prime}\right)$ of amino acid residue, ' $i$ ', which is selectively unlabeled. The experiments, namely, 2D HN(CA) $(i+$ 1), GFT $(3,2) \mathrm{D} \mathrm{HNCACB}(i+1)$ and GFT $(3,2) \mathrm{D} \mathrm{HNCACO}(i+1)$ are further accelerated by employing non-uniform sampling (NUS) [20-26]. The methodology is demonstrated on a selectively unalabeled protein sample of ubiquitin. Its application to larger proteins is discussed.

\section{Results}

\subsection{Implementation of NMR Experiments}

All the experiments proposed are "HNCA" [5] based and involve the transfer of ${ }^{15} \mathrm{~N}$ magnetization of residue $i+1\left({ }^{15} \mathrm{~N}_{i+1}\right)$ to ${ }^{13} \mathrm{C}^{\alpha}{ }_{i+1}$ or ${ }^{13} \mathrm{CO}_{i+1}$. They, however, detect selectively the resonances $\left({ }^{1} \mathrm{H} /{ }^{13} \mathrm{C} /{ }^{15} \mathrm{~N}\right)$ of residue $i+1$ corresponding to the selectively unlabeled residue, $i$. This selection is achieved by tuning the delay periods in the radio frequency (r.f.) pulse sequence appropriately such that the magnetization on ${ }^{15} \mathrm{~N}_{i+1}$ is attenuated by coupling to both ${ }^{13} \mathrm{CO}_{i}$ and ${ }^{13} \mathrm{C}^{\alpha}{ }_{i}$ by one-bond and two-bond scalar couplings, ${ }^{1} \mathrm{~J}_{\mathrm{NCO}}(\sim 15 \mathrm{~Hz})$ and ${ }^{2} \mathrm{~J}_{\mathrm{NC} \alpha}(\sim 7 \mathrm{~Hz})$, respectively. For this purpose, a delay period of $1 / 2 \mathrm{~J}(\mathrm{~J}$ is the scalar coupling) is used which converts an in-phase magnetization of a nuclei to anti-phase magnetization with respect to its J-coupled partner. This is depicted schematically in Figure 1a. In the case where both residues $i$ and $i+1$ are ${ }^{13} \mathrm{C},{ }^{15} \mathrm{~N}$ labeled, ${ }^{15} \mathrm{~N}_{i+1}$ magnetization is attenuated by the scalar coupling evolution to ${ }^{13} \mathrm{CO}_{i}$ and ${ }^{13} \mathrm{C}^{\alpha}{ }_{i}$ (passive coupling via ${ }^{2} \mathrm{~J}_{\mathrm{NC} \alpha}$ ). Thus, if residue $i$ is a labeled $\left({ }^{13} \mathrm{C} /{ }^{15} \mathrm{~N}\right)$ residue the chemical shift correlations from its neighbor: $i+1$ are not detected. However, if the residue $i$ among a given pair $(i, i+1)$ is unlabeled (i.e., ${ }^{12} \mathrm{C} /{ }^{14} \mathrm{~N}$ ), ${ }^{15} \mathrm{~N}_{i+1}$ is coupled only to ${ }^{13} \mathrm{C}^{\alpha}{ }_{i+1}$ and hence the delay period of $1 / 2 \mathrm{~J}$ corresponding to ${ }^{1} \mathrm{~J}_{\mathrm{NCO}}$ and ${ }^{2} \mathrm{~J}_{\mathrm{NC} \alpha}$ has no effect and ${ }^{15} \mathrm{~N}_{i+1}$ magnetization gets selected (product operator treatment is discussed below).

The delay periods used in the r.f. pulse schemes are thus optimized to achieve minimal selection of labeled $(i, i+1)$ pair while maximizing the intensity of unlabeled $(i)$-labeled $(i+1)$ pair. Since the experiments are "HNCA" type, the transfer function for the desired or selected ${ }^{15} \mathrm{~N}_{i+1}$ magnetization (from unlabeled $i$-labeled $i+1$ pair) and undesired or suppressed ${ }^{15} \mathrm{~N}_{i+1}$ magnetization (in case of labeled $i, i+1$ pair) during the filter element ' $a$ ' shown in Figure 1a can be expressed (ignoring relaxation) as:

$$
\begin{gathered}
\Gamma \text { (selected): } \sin \left(\pi^{1} \mathrm{~J}_{\mathrm{NC} \alpha} \tau_{\mathrm{NC} \alpha}\right) \\
\Gamma \text { (suppressed): } \sin \left(\pi^{1} \mathrm{~J}_{\mathrm{NC} \alpha} \tau_{\mathrm{NC} \alpha}\right) \times \cos \left(\pi^{2} \mathrm{~J}_{\mathrm{NC} \alpha} \tau_{\mathrm{NC} \alpha}\right)
\end{gathered}
$$

where $\tau_{\mathrm{NC} \alpha}$ is the delay period during which ${ }^{15} \mathrm{~N}_{i+1}$ is coupled passively to ${ }^{13} \mathrm{C}^{\alpha}{ }_{i}$ via ${ }^{2} \mathrm{~J}_{\mathrm{NC}}$ if residue $i$ is labeled. Next, during this period the ${ }^{15} \mathrm{~N}_{i+1}$ is also allowed to couple with ${ }^{13} \mathrm{CO}_{i}$ (for labeled $i-i+1$ pair) for the duration $\tau_{\mathrm{HNC}^{\prime}}\left(\sim 1 / 2^{1} \mathrm{~J}_{\mathrm{NCO}}\right)$ and the transfer function above gets modified as:

$$
\begin{gathered}
\Gamma \text { (selected): } \sin \left(\pi^{1} \mathrm{~J}_{\mathrm{NC} \alpha} \tau_{\mathrm{NC} \alpha}\right) \\
\Gamma \text { (supressed): } \sin \left(\pi^{1} \mathrm{~J}_{\mathrm{NC} \alpha} \tau_{\mathrm{NC} \alpha}\right) \times \cos \left(\pi^{2} \mathrm{~J}_{\mathrm{NC} \alpha} \tau_{\mathrm{NC} \alpha}\right) \times \cos \left(\pi^{1} \mathrm{~J}_{\mathrm{NCO}} \tau_{\mathrm{NCO}}\right)
\end{gathered}
$$

where $\tau_{\mathrm{NCO}}$ is the delay period during which ${ }^{15} \mathrm{~N}_{i+1}$ is coupled to ${ }^{13} \mathrm{CO}_{i}$ via ${ }^{1} \mathrm{~J}_{\mathrm{NCO}}$. Figure $1 \mathrm{~b}$ depicts a plot of the transfer function as a function of $\tau_{\mathrm{NC} \alpha}$ delays. Also shown in the figure is a plot of ratio of $\Gamma$ (selected) $/ \Gamma$ (suppressed), which is maximum for $\tau_{\mathrm{NC} \alpha} \sim 43 \mathrm{~ms}$ and $\tau_{\mathrm{NCO}} \sim 33 \mathrm{~ms}$ (assuming ${ }^{1} \mathrm{~J}_{\mathrm{NCO}}$ $=15 \mathrm{~Hz},{ }^{1} \mathrm{~J}_{\mathrm{NC} \alpha}=11 \mathrm{~Hz}$ and ${ }^{2} \mathrm{~J}_{\mathrm{NC} \alpha}=7 \mathrm{~Hz}$ ). Variations in ${ }^{1} \mathrm{~J}_{\mathrm{NCO}},{ }^{1} \mathrm{~J}_{\mathrm{NC} \alpha}$ and ${ }^{2} \mathrm{~J}_{\mathrm{NC} \alpha}$ among different secondary structural elements has been ignored. 

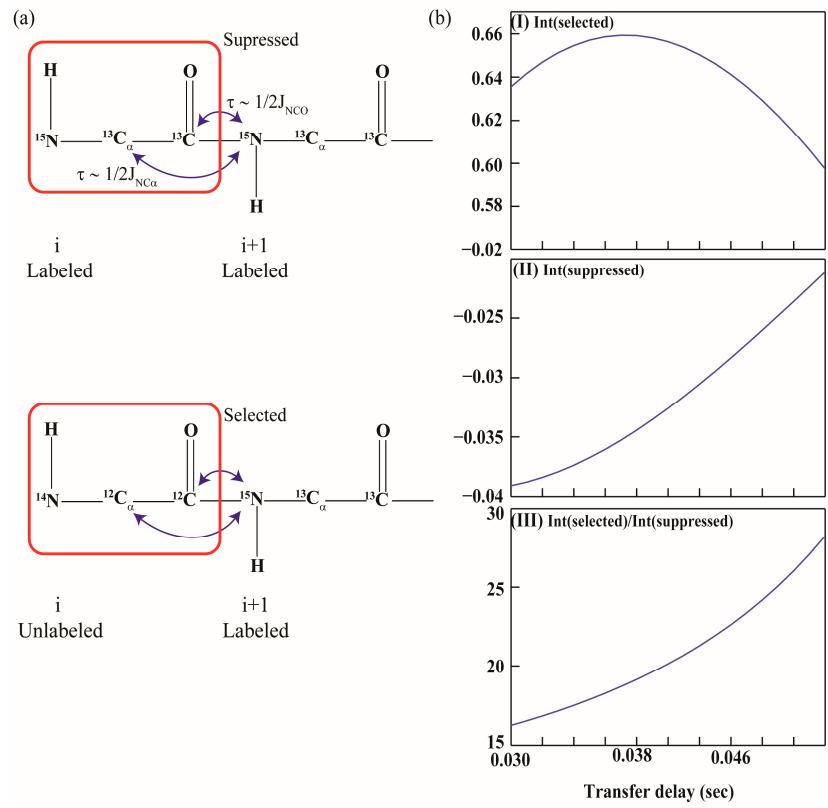

Figure 1. (a) Schematic illustration of the selection of magnetization in all the filter experiments employing one-bond and two-bond scalar couplings, ${ }^{1} \mathrm{~J}_{\mathrm{NCO}}(\sim 15 \mathrm{~Hz})$ and ${ }^{2} \mathrm{~J}_{\mathrm{NC} \alpha}(\sim 7 \mathrm{~Hz})$, respectively; (b) Figure $1 \mathrm{~b}$ shows a plot of the transfer function as a function of $\tau_{\mathrm{NC} \alpha}$ delays. Panels (I), (II) and (III) shows variation of $\Gamma$ (selected), $\Gamma$ (suppressed) the ratio of $\Gamma$ (selected) $/ \Gamma$ (suppressed) as a function of $\tau_{\mathrm{NC} \alpha}$ delays respectively.

The above selection scheme was implemented in the $2 \mathrm{D} \operatorname{HN}(\mathrm{CA})(i+1)$, GFT $(3,2) \mathrm{D} \operatorname{HNCACB}(i$ $+1)$ and GFT $(3,2) \mathrm{D} H N(\mathrm{CA}) \mathrm{CO}(i+1)$ the r.f. pulse schemes of which are shown in Figure 2. The first experiment, 2D HN(CA) $(i+1)$ provides a $2 \mathrm{D}\left[{ }^{15} \mathrm{~N}_{i+1},{ }^{1} \mathrm{H}_{i+1}\right]$ correlation spectrum analogues to a $2 \mathrm{D}\left[{ }^{15} \mathrm{~N},{ }^{1} \mathrm{H}\right]$ HSQC spectrum. The delay periods $\tau_{\mathrm{NC} \alpha}$ and $\tau_{\mathrm{NCO}}$ in Equations (1)-(4) above correspond to $2 * \tau_{3}$ and $2 *\left(\tau_{3}-\tau_{4}\right)$ and, respectively. In the $(3,2) \mathrm{D}$ GFT experiments, for nuclei shown underlined (e.g., $\mathrm{N}$ and $\mathrm{CO}$ in $(3,2) \mathrm{D} \mathrm{HN}(\mathrm{CA}) \mathrm{CO}(i+1))$, chemical shifts are jointly sampled. That is, the chemical shift evolution periods of ${ }^{15} \mathrm{~N}$ and ${ }^{13} \mathrm{CO}$ are co-incremented resulting in sums and differences of chemical shifts $[1,2,18]$. Thus, the following shift correlations are detected in the GFT ( $\left.\omega_{1}\right)$ dimension: (i) $\Omega\left({ }^{15} \mathrm{~N}_{i+1} \pm \kappa^{* 13} \mathrm{C}^{\alpha}{ }_{i+1}\right), \Omega\left({ }^{15} \mathrm{~N}_{i+1} \pm \kappa^{* 13} \mathrm{C}^{\beta}{ }_{i+1}\right)$ in $(3,2) \mathrm{D} \mathrm{HNCACB}(i+1)$ and (ii) $\Omega\left({ }^{15} \mathrm{~N}_{i+1} \pm \mathrm{k}{ }^{* 13} \mathrm{CO}_{i+1}\right)$ in $(3,2) \mathrm{D} \mathrm{HN}(\mathrm{CA}) \mathrm{CO}(i+1)$. The factor, $\mathrm{k}$, scales the relative shifts of ${ }^{13} \mathrm{C}^{\alpha}{ }_{i+1}$, ${ }^{13} \mathrm{C}^{\beta}{ }_{i+1}$ in $(3,2) \mathrm{D} \mathrm{HNCACB}(i+1)$ and $\mathrm{CO}_{i+1}$ in $(3,2) \mathrm{D} \mathrm{HN}(\mathrm{CA}) \mathrm{CO}(i+1)$ with respect ${ }^{15} \mathrm{~N}_{i+1}$ (Figure 2). In all spectra acquired in the present study $\mathrm{K}=0.5$ was used. The ${ }^{15} \mathrm{~N}_{i+1}$ serves as the center shift and hence 2D HN(CA) $(i+1)$ providing $\left[{ }^{1} \mathrm{H}_{i+1},{ }^{15} \mathrm{~N}_{i+1}\right]$ shift correlations serves the central peak spectrum.

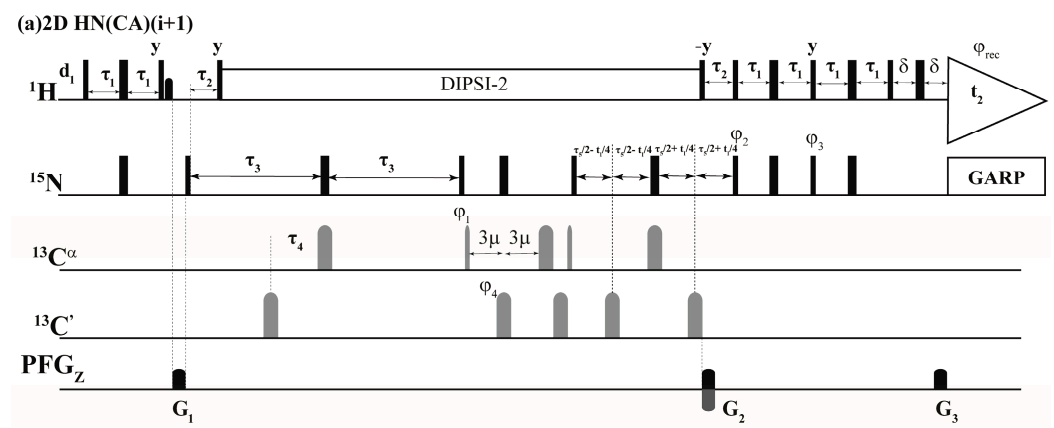

Figure 2. Cont. 
(b) GFT (3,2)D HN(CA) $\underline{\mathbf{C O}}(i+1)$

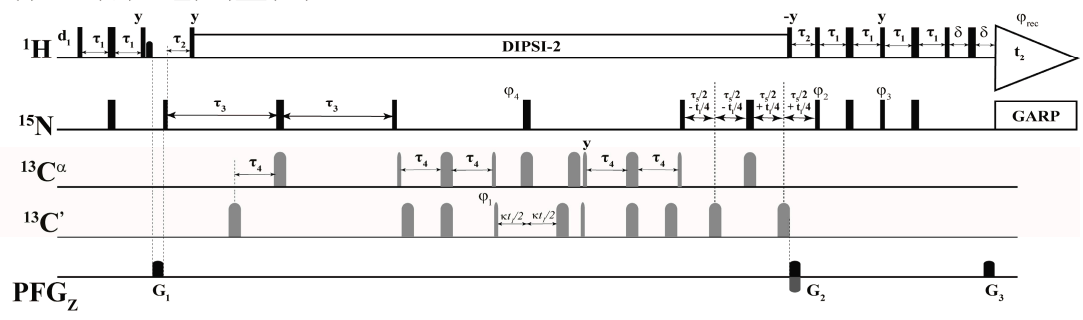

(c) GFT (3,2)D HNCACB $\underline{\text { (i+1) }}$

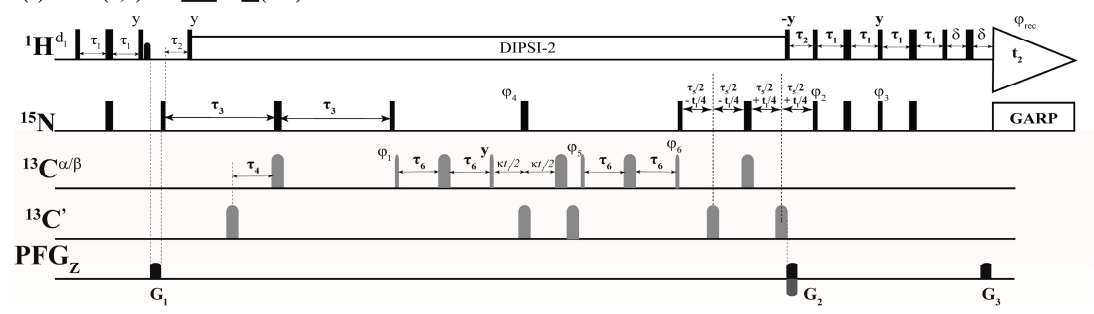

Figure 2. Radio frequency (r.f.) pulse sequences of (a) $2 \mathrm{D} \mathrm{HN}(\mathrm{CA})(i+1)$; (b) $\mathrm{GFT}(3,2) \mathrm{D} \mathrm{HN}(\mathrm{CA}) \mathrm{CO}(i+1)$ and $(\mathrm{c})$ GFT $(3,2) \mathrm{D} \mathrm{HNCACB}(i+1)$. Rectangular $90^{\circ}$ and $180^{\circ}$ hard pulses on ${ }^{1} \mathrm{H}$ and ${ }^{15} \mathrm{~N}$ channel are indicated by thin and thick vertical bars, respectively and the same thin and thick notations are used for $90^{\circ}$ and $180^{\circ}$ shape pulses in ${ }^{13} \mathrm{C}$ channel. The representative $90^{\circ}$ pulse widths are $11.5 \mu \mathrm{s}, 37.5 \mu \mathrm{s}$ and $9.8 \mu$ s for ${ }^{1} \mathrm{H},{ }^{15} \mathrm{~N}$ and ${ }^{13} \mathrm{C}$ channels respectively. The corresponding phases of the applied pulses are indicated above and in places where no r.f. phase is marked, the pulse is applied along $x$. The ${ }^{1} \mathrm{H}$ offset is placed at the position of the solvent line at $4.7 \mathrm{ppm}$ and the ${ }^{15} \mathrm{~N}$ carrier was adjusted according to the spectral width observed in ${ }^{15} \mathrm{~N}$ dimension which was $119.5 \mathrm{ppm}$ for Ubiquitin. The ${ }^{13} \mathrm{C}^{\alpha}$ r.f. carrier was placed at $54 \mathrm{ppm}$ throughout the sequence and ${ }^{13} \mathrm{C}^{\prime}$ carrier frequency was set at $176.0 \mathrm{ppm}$. The shaped pulse on ${ }^{13} \mathrm{C}^{\alpha}$ are of Gaussian cascade type with a pulse width of $240 \mu \mathrm{s}$ and $196 \mu$ s, respectively, for $90^{\circ}$ and $180^{\circ}$ on resonance. The $180^{\circ}$ off resonance pulse (Gaussian cascade) on ${ }^{13} \mathrm{C}^{\prime}$ was applied for duration of $192 \mu \mathrm{s}$. In (a) DIPSI-2 is employed for decoupling ${ }^{1} \mathrm{H}$ during ${ }^{15} \mathrm{~N}$ shift evolution periods and in other cases $(\mathbf{b}, \mathbf{c}),{ }^{15} \mathrm{~N}$ and ${ }^{13} \mathrm{C}$ chemical shifts were jointly incremented. GARP was employed to decouple ${ }^{15} \mathrm{~N}$ during acquisition (r.f. strength $=3 \mathrm{kHz}$ ) all the sequences. All pulsed z-field gradients (PFGs) are sinc shaped with gradient recovery delay of $200 \mu \mathrm{s}$. The duration of gradient was $1.0 \mathrm{~ms}$ each and the strengths of the PFGs were G1: $16 \mathrm{G} / \mathrm{cm}, \mathrm{G} 2: 43 \mathrm{G} / \mathrm{cm}, \mathrm{G} 3: 4.3 \mathrm{G} / \mathrm{cm}$. The delays and the phase cycling employed were as follows: For (a) $2 \mathrm{D} \mathrm{HN}(\mathrm{CA})(i+1)$, delays employed were $\tau_{1}=2.3 \mathrm{~m}$, $\tau_{2}=5.5 \mathrm{~m}, \tau_{3}=21.5 \mathrm{~m}, \tau_{4}=4.5 \mathrm{~m}, \tau_{5}=12 \mathrm{~m}$ and Phase cycling: $\varphi_{2}=2(x), 2(-x) ; \varphi_{3}=2(-y), 2(y) ; \varphi_{4}=$ $4(x), 4(-x) ; \varphi_{5}=8(x), 8(-x)$ and $\varphi_{\text {rec }}=2(x,-x,-x, x), 2(-x, x, x,-x)$. For $(\mathbf{b})$ GFT $(3,2) \mathrm{D} \mathrm{HN}(\mathrm{CA}) \mathrm{CO}(i+$ $1)$, same delays were employed and Phase cycling: $\varphi_{1}=x,-x ; \varphi_{2}=2(x), 2(-x) ; \varphi_{3}=2(-y), 2(y) ; \varphi_{4}=$ $4(x), 4(-x)$ and $\varphi_{\text {rec }}=2(x,-x,-x, x), 2(-x, x, x,-x)$. For GFT NMR: two data sets with phase cycle $\varphi_{1}$ $=(x),(-x)$ and $(y),(-y)$ were acquired, in conjunction with quadrature detection in ${ }^{15} \mathrm{~N}$ which were linearly combined later employing a G-matrix transformation. For $(\mathbf{c})$ GFT $(3,2) \mathrm{D} \operatorname{HNCACB}(i+1)$, delays employed were $\tau_{1}=2.3 \mathrm{~m}, \tau_{2}=5.5 \mathrm{~m}, \tau_{3}=21.5 \mathrm{~m}, \tau_{4}=1 \mathrm{~m}, \tau_{5}=12.5 \mathrm{~m}$ and $\tau_{6}=3.6 \mathrm{~m}$. Phase cycling: $\varphi_{1}=x ; \varphi_{2}=2(x), 2(-x) ; \varphi_{3}=2(-y), 2(y) ; \varphi_{4}=2(x), 2(-x)$ and $\varphi_{\text {rec }}=2(x,-x,-x, x), 2(-x, x, x,-x)$. For GFT NMR: two data sets with phase cycle $\varphi_{5}=(-y),(y)$ along with $\varphi_{6}=2(x,-x), 2(-x, x)$ and $\varphi_{5}=$ $(x),(-x)$ along with $\varphi_{6}=2(y,-y), 2(-y, y)$ were acquired, in conjunction with quadrature detection in ${ }^{15} \mathrm{~N}$ and later were linearly combined employing a G-matrix transformation. Quadrature detection in $t_{2}\left({ }^{15} \mathrm{~N}\right)$ is accomplished using the sensitivity enhanced scheme by inverting the sign of gradient $\mathrm{G}_{2}$ in concert with phases $\varphi_{3}$. Chemical shift evolution in ${ }^{15} \mathrm{~N}$ channel $\left(t_{2}\right)$ is achieved in a constant manner ' $K$ ' is the scaling factor. For GFT experiments, at the same time ${ }^{13} \mathrm{C}$ chemical shift evolution period is co-incremented leading to the linear combination: (b) $\Omega\left({ }^{15} \mathrm{~N}_{i+1} \pm \mathrm{K} *{ }^{13} \mathrm{CO}_{i+1}\right)$ in $(3,2) \mathrm{D} \mathrm{HN}(\mathrm{CA}) \mathrm{CO}(i$ $+1)$ and (c) $\Omega\left({ }^{15} \mathrm{~N}_{i+1} \pm \mathrm{k} *{ }^{13} \mathrm{C}^{\alpha}{ }_{i+1}\right), \Omega\left({ }^{15} \mathrm{~N}_{i+1} \pm \mathrm{K} *{ }^{13} \mathrm{C}^{\beta}{ }_{i+1}\right)$ in $(3,2) \mathrm{D} \mathrm{HNCACB}(i+1)$ respectively. In all spectra acquired in the present study $\mathrm{K}=0.5$ was used. 


\subsection{Resonance Assignment Strategy}

Using the above set of experiments, resonance assignment is carried out as follows. For each $\left[{ }^{15} \mathrm{~N}_{i+1},{ }^{1} \mathrm{H}_{i+1}\right]$ chemical shifts identified in $2 \mathrm{D} \mathrm{HN}(\mathrm{CA})(i+1)$, the amino acid type corresponding to residue $i+1$ (self) is identified using (3,2)D $\mathrm{HNCACB}(i+1)$ based on ${ }^{13} \mathrm{C}^{\alpha}{ }_{i+1},{ }^{13} \mathrm{C}^{\beta}{ }_{i+1}$ values. Similarly using the $(3,2) \mathrm{D} \mathrm{HN}(\mathrm{CA}) \mathrm{CO}(i+1)$ the $\mathrm{CO}_{i+1}$ shifts are identified. Once the identity of the amino acid type corresponding to $i+1$ is identified, and given that the amino acid type of $i$ is known which is selectively unlabeled, the dipeptide pair $i-i+1$ can be mapped onto the primary sequence for sequence-specific resonance assignment. Note that this is approach, that is different from the conventional strategy where the di-peptide pairs $i-i-1$ are identified using 3D HNCACB and $3 \mathrm{D}$ CBCA(CO)NH for given residue $i$. Thus, the GFT experiments using selectively unlabeling can augment the conventional assignment approach resulting in a tri-peptide stretch $(i-1, i, i+1)$ around a selectively unlabeled residue $i$. This is depicted in Figure 3. The experiments presented here thus increase the assignment speed compared to the approach presented earlier which did not yield directly the ${ }^{13} \mathrm{C}^{\alpha}{ }_{i+1},{ }^{13} \mathrm{C}^{\beta}{ }_{i+1}$ shifts.

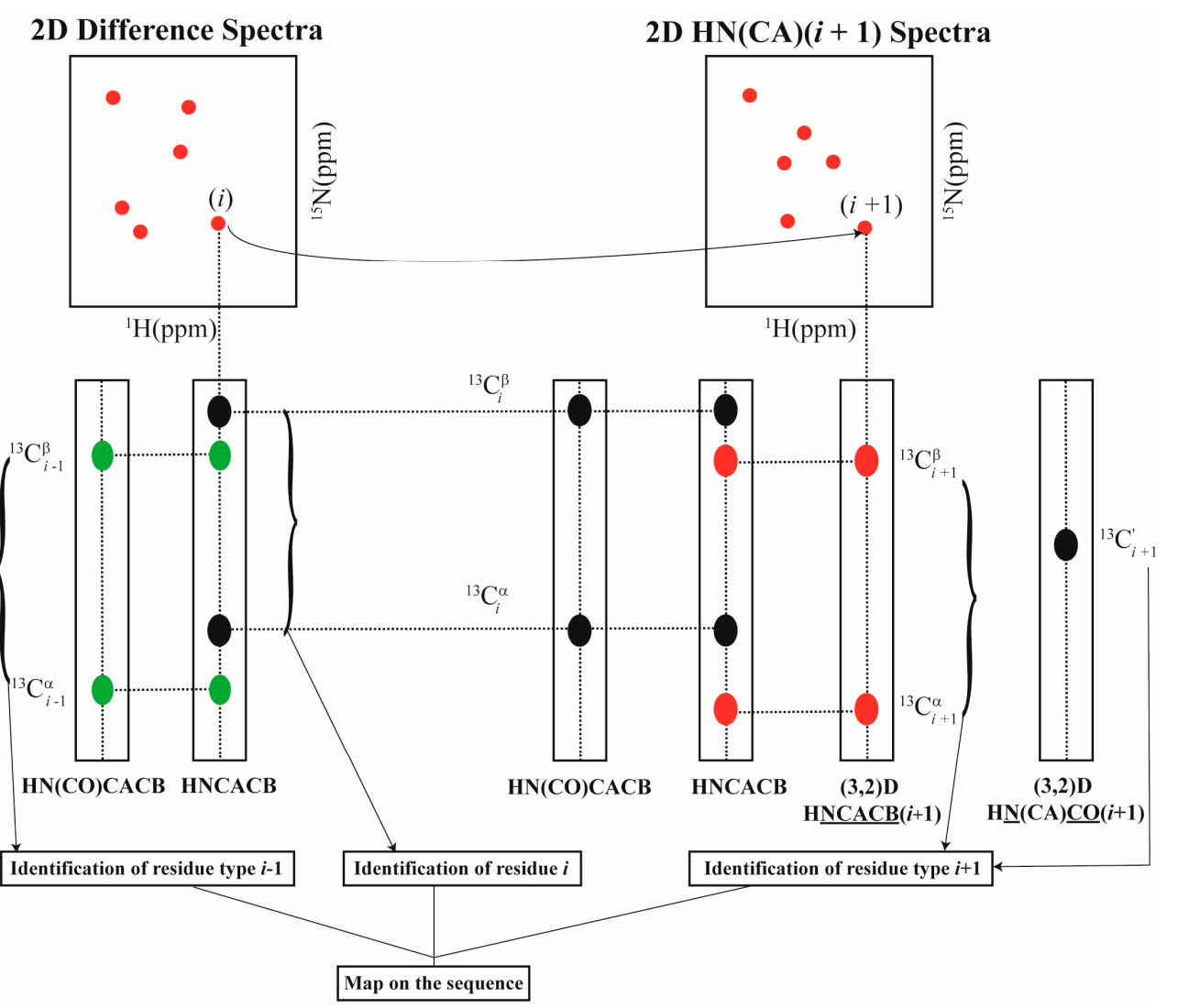

Figure 3. Schematic illustration of the sequential assignment strategy used with selective unlabeling.

In a given sample, more than one amino acid type can be chosen for simultaneous selective unlabeling so that the number of samples to be prepared is minimized. Two or more amino acid types are chosen for selectively unlabeling such that their ${ }^{13} \mathrm{C}^{\beta}{ }_{i+1}$ shifts lie in distinct spectral regions enabling their type identification. For instance, in the current study, Arg and Asn were used for selective unlabeling in the same sample due to their distinct ${ }^{13} \mathrm{C}^{\beta}{ }_{i+1}$ shifts. However, in such cases the $\left[{ }^{15} \mathrm{~N}_{i+1},{ }^{1} \mathrm{H}_{i+1}\right]$ pair of shifts obtained from $2 \mathrm{D} \mathrm{HN}(\mathrm{CA})(i+1)$ do not provide any information directly on the type of amino acid residue $i$. Hence, a 3D CBCA(CO)NH spectrum acquired on the uniformly ${ }^{13} \mathrm{C},{ }^{15} \mathrm{~N}$ labeled sample is needed. In the $3 \mathrm{D} \mathrm{CBCA}(\mathrm{CO}) \mathrm{NH}$ spectrum, at a given $\left[{ }^{15} \mathrm{~N}_{i+1},{ }^{1} \mathrm{H}_{i+1}\right]$ pair 
of shifts, the amino acid type corresponding to residue $i$ can be identified based on ${ }^{13} \mathrm{C}^{\alpha}{ }_{i}{ }^{13} \mathrm{C}^{\beta}{ }_{i}$ values (Figure 3).

\subsection{Data Acquisition Using Non-Uniform Sampling (NUS)}

The measurement time required for acquiring the GFT spectra can be reduced further by using the non-uniform sampling (NUS) approach [24-26]. The NUS approach is based on the premise that the conventional method involving linear sampling of interferogram in the inderct dimension requires a lot more number of points although the number of frequencies encoded in the interferogram is much less. Thus, by reducing the number of sampling points in the indirect dimensions the total measurement time can be proportionately reduced. The dataset obtained using NUS is then reconstructed either in the time domain using the multiway decomposition method (MDD) or directly in the frequency domain using the maximum entropy reconstruction (MER) approach. The sampling points are chosen based on the decay of the Free Induction Decay (FID). In case of a constant time experiment, the NUS points can be chosen randomly. In the present study, the MDD approach was used for spectral reconstruction in the time domain. The data were acquired a random sampling of $25 \%$ of the points (i.e., the omission of $75 \%$ of the time domain points) in the GFT dimension.

Figure 4a shows an overlay of the $2 \mathrm{D}\left[{ }^{15} \mathrm{~N},{ }^{1} \mathrm{H}\right] \mathrm{HSQC}$ spectrum of the uniformly ${ }^{13} \mathrm{C},{ }^{15} \mathrm{~N}$ labeled (shown in red) and Arg, Asn selectively unlabeled (in blue) ubiquitin. The resonances, which are absent in the selectively unlabeled sample, corresponding to Arg and Asn residues as indicated. No other residues were observed to be absent indicating minimal mis-incorporation of ${ }^{14} \mathrm{~N}$ isotope of Arg and Asn (also referred to as 'isotope scrambling'). Figure $4 \mathrm{~b}$ shows $2 \mathrm{D} \mathrm{HN}(\mathrm{CA})(i+1)$ spectrum acquired on the Arg, Asn selectively unlabeled sample. All expected $\left[{ }^{15} \mathrm{~N}_{i+1},{ }^{1} \mathrm{H}_{i+1}\right]$ correlations are observed in the spectrum as indicated.

\section{MQIFVKTLTGKTITLEVEPSDTIENVKAKIQDKEGIPPDQQRLIFAGK QLEDGRTLSDYNIQKESTLHLVLRLRGG}

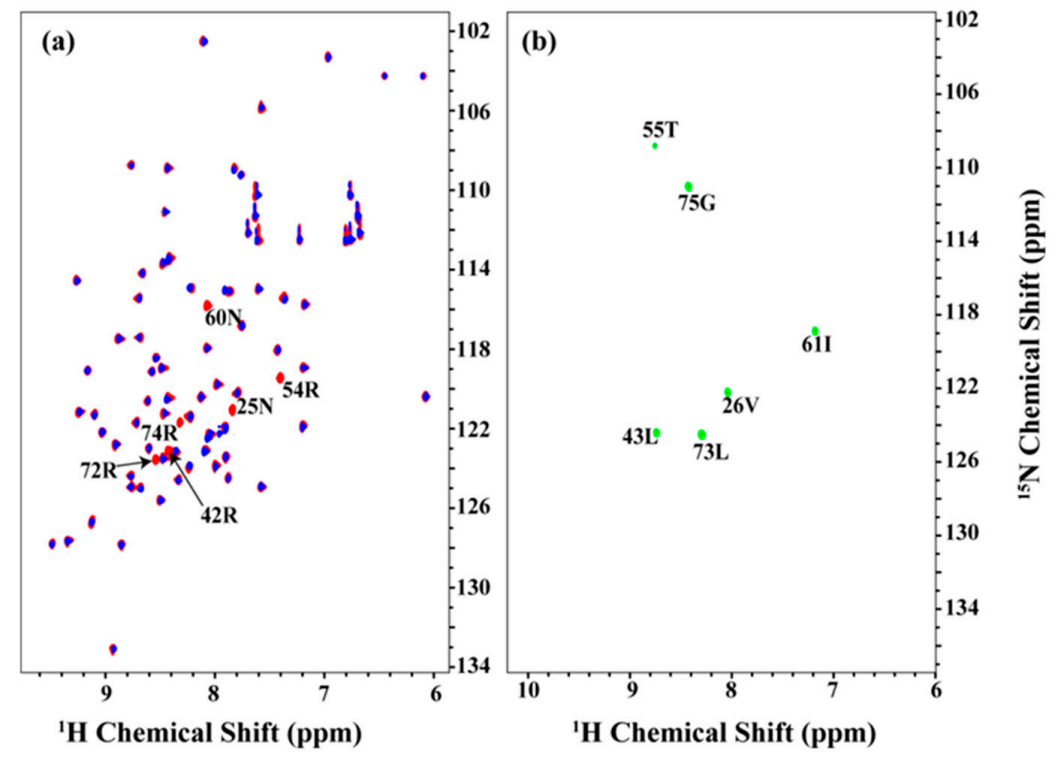

Figure 4. (a) overlay of the 2D $\left[{ }^{15} \mathrm{~N},{ }^{1} \mathrm{H}\right]$ HSQC spectrum of the uniformly ${ }^{13} \mathrm{C},{ }^{15} \mathrm{~N}$ labeled ubiquitin as shown in red and Arg, Asn selectively unlabeled sample as shown in blue; (b) 2D $\mathrm{HN}(\mathrm{CA})(i+1)$ spectrum acquired on the Arg, Asn selectively unlabeled sample. Assignments are indicated on the spectra. The sequence is shown above and the unlabeled residues are highlighted in red.

Figures 5 and 6 show the (3,2)D $\operatorname{HNCACB}(i+1)$ and $(3,2) \mathrm{D} \operatorname{HN}(\mathrm{CA}) \mathrm{CO}(i+1)$ of $\mathrm{Arg}$, Asn selectively unlabeled sample of ubiquitin acquired in 54 and $35 \mathrm{~min}$ with 8 scans each for both datasets, respectively. All expected ${ }^{13} \mathrm{C}^{\alpha}{ }_{i+1},{ }^{13} \mathrm{C}^{\beta}{ }_{i+1}$ and ${ }^{13} \mathrm{CO}_{i+1}$ correlations except that of $55 \mathrm{~T}$ are observed. 
The correlation of $55 \mathrm{~T}$ is presumably absent due to its weak intensity in the HSQC spectrum and shorter transverse relaxation time of its ${ }^{13} \mathrm{C}$ nuclei. The ${ }^{13} \mathrm{C}^{\alpha}{ }_{i+1},{ }^{13} \mathrm{C}^{\beta}{ }_{i+1}$ and ${ }^{13} \mathrm{CO}_{i+1}$ chemical shifts values are obtained by linearly combining the sums and differences of the chemical shifts observed in the two GFT sub-spectra of each experiment and taking into account the appropriate scaling factor. Note that a 3D spectrum with an equivalent resolution would have taken more than 3 days of measurement time (2 days $7 \mathrm{~h} 9 \mathrm{~min}$ for 3D $\mathrm{HNCACB}(i+1)$ and $19 \mathrm{~h} 23 \mathrm{~min}$ for 3D HN(CA)CO $(i+1)$ ). Thus, the GFT experiments potentially reduce the measurement time by about an order of magnitude.

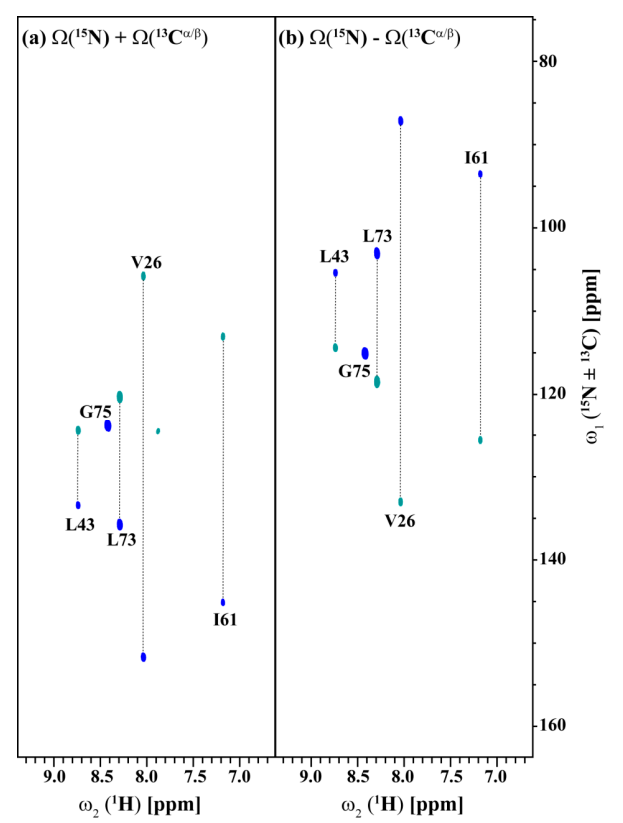

Figure 5. (a,b) shows the different linear combinations of $(3,2) \mathrm{D} \operatorname{HNCACB}(i+1)$ of $\operatorname{Arg}$, Asn selectively unlabeled sample of ubiquitin. Total measurement time for two spectra was 54 min with 8 scans each. Peaks shown in blue and green correspond to $\Omega\left({ }^{15} N_{i+1} \pm{ }^{*}{ }^{13} C^{\alpha}{ }_{i+1}\right)$ and $\Omega\left({ }^{15} N_{i+1} \pm \kappa{ }^{* 13} C^{\beta}{ }_{i+1}\right)$, respectively. The scaling factor $\mathrm{k}$ was set to 0.5 .

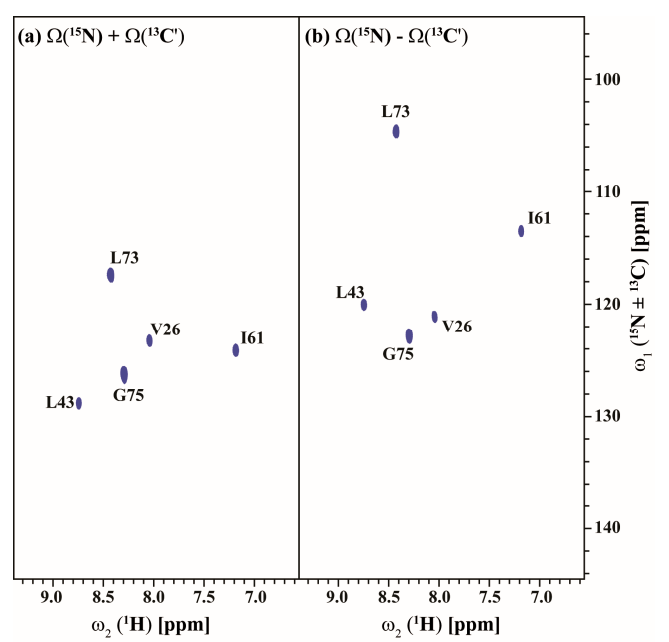

Figure 6. (a,b) shows the different linear combinations of $(3,2) \mathrm{D} H \mathrm{HN}(\mathrm{CA}) \mathrm{CO}(i+1)$ of $\mathrm{Arg}$, $\mathrm{Asn}$ selectively unlabeled sample of ubiquitin. Total measurement time for two spectra was 35 min with 8 scans each. Peaks shown in blue in figure (a,b) correspond to $\Omega\left({ }^{15} N_{i+1}+K^{*}{ }^{13} C^{\prime}{ }_{i+1}\right)$ and $\Omega\left({ }^{15} N_{i+1}{ }^{-k}\right.$ * $\left.{ }^{13} C^{\prime}{ }_{i+1}\right)$, respectively. The scaling factor $\mathrm{k}$ was set to 0.5 . 
The acquisition of GFT spectra is further accelerated using the NUS approach. Figures 7 and 8 show the $25 \%$ NUS spectrum of $(3,2) \mathrm{D} \mathrm{HNCACB}(i+1)$ and $(3,2) \mathrm{D} \mathrm{HN}(\mathrm{CA}) \underline{\mathrm{CO}}(i+1)$ experiments acquired in less than 14 and 9 min respectively. All expected correlations as observed in the non-NUS counterparts are observed without any spectral distortions or artifacts. The signal-to-noise ratio $(\mathrm{S} / \mathrm{N})$ by NUS is not compromised as shown in Figure $7 \mathrm{c}, \mathrm{d}$ and Figure $8 \mathrm{c}, \mathrm{d}$ which compares the 1D traces from the non-NUS and NUS GFT data.
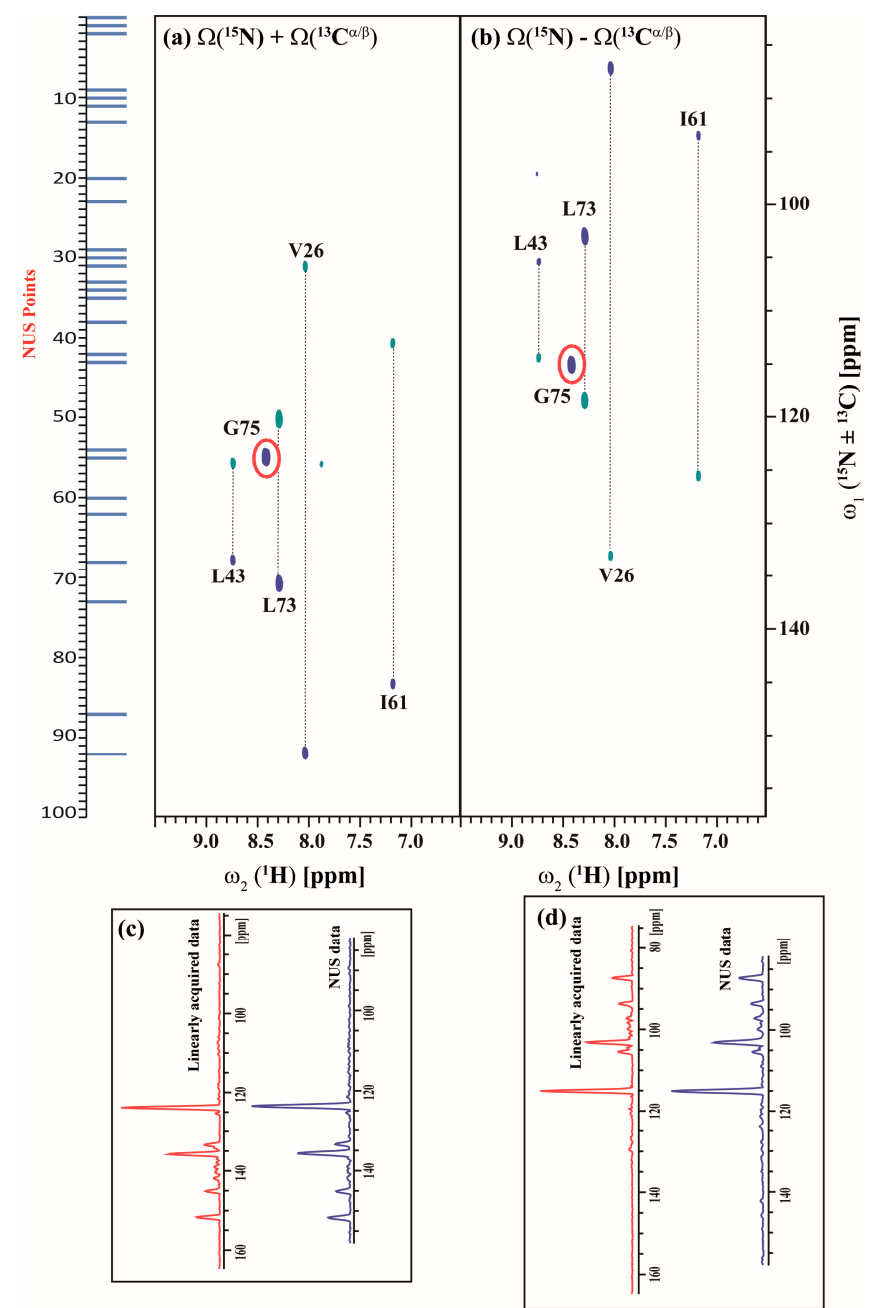

Figure 7. (a,b) shows the different linear combinations of non-uniformly sampled $(3,2) \mathrm{D}$ HNCACB $i+$ 1) of Arg, Asn selectively unlabeled sample of ubiquitin. Total measurement time for two spectra was 14 min with 8 scans each. Peaks shown in blue and green correspond to $\Omega\left({ }^{15} \mathrm{~N}_{i+1} \pm \mathrm{K}^{*}{ }^{13} \mathrm{C}^{\alpha}{ }_{i+1}\right)$ and

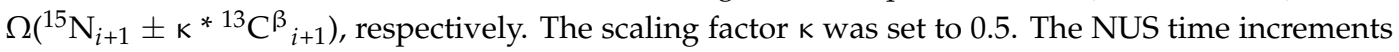
in the shared dimension which was actually acquired in the experiment are shown in blue bars; (c,d), represents the overlay of 1D projection of linearly acquired data (red) and non-uniformly acquired data (blue) along $\omega_{1}$ for $\Omega\left({ }^{15} N_{i+1}+\kappa{ }^{* 13} C^{\alpha}{ }_{i+1} /{ }^{13} C^{\beta}{ }_{i+1}\right)$ and $\Omega\left({ }^{15} N_{i+1}-\kappa{ }^{* 13} C^{\alpha}{ }_{i+1} /{ }^{13} C^{\beta}{ }_{i+1}\right)$ respectively. There is $28 \%$ reduction in signal to noise (SNR) ratio ongoing from linearly acquired data to NUS data as measured by the SNR of the projections. We also have calculated SNR of G75 (highlighted in red) individually and there also we have seen $\sim 30 \%$ decrease in SNR on going from linearly acquired data to NUS data. 


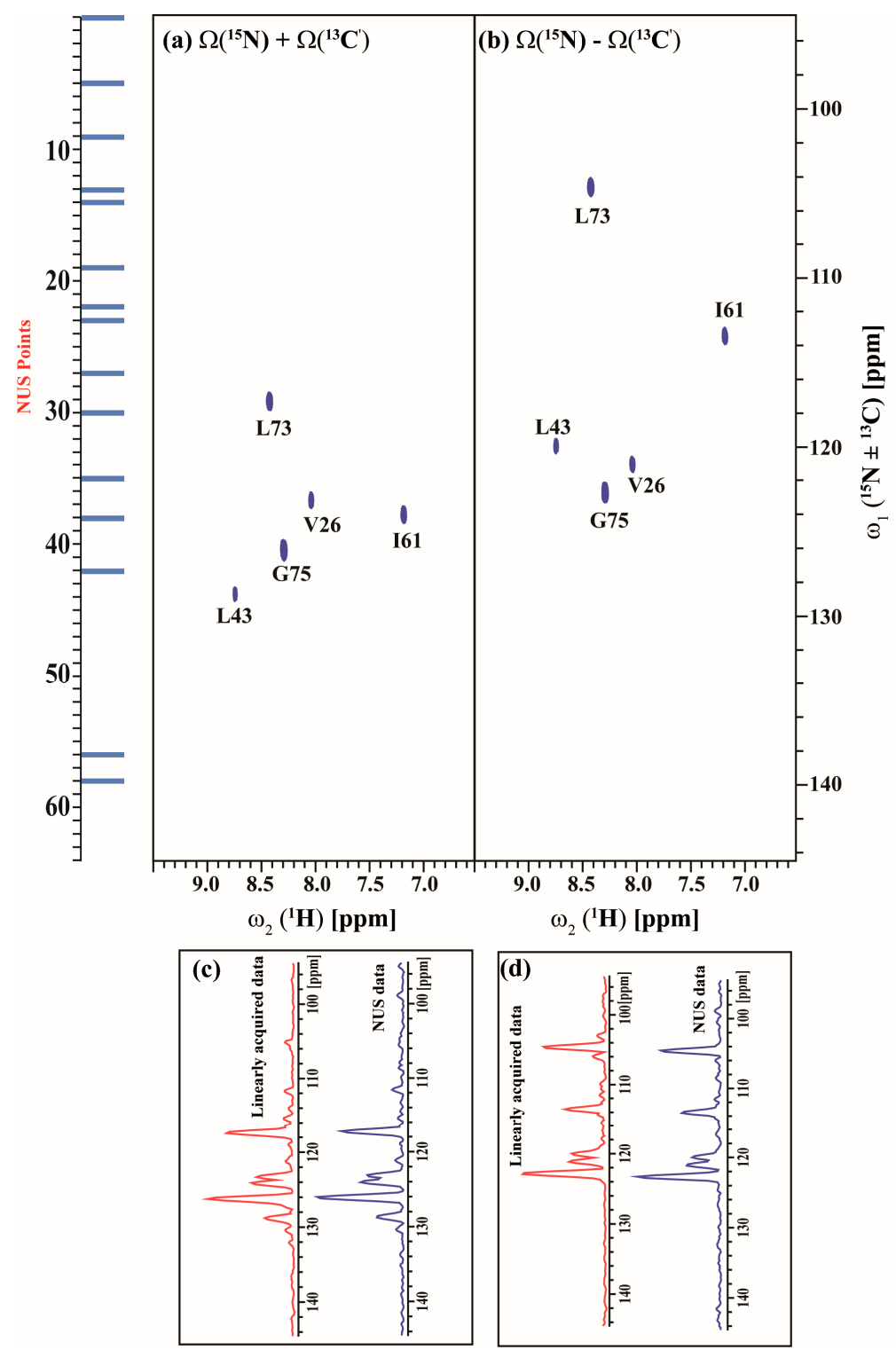

Figure 8. (a,b) shows the different linear combinations of non-uniformly sampled $(3,2) \mathrm{D} H \mathrm{HN}(\mathrm{CA}) \mathrm{CO}(i$ +1 ) of Arg, Asn selectively unlabeled sample of ubiquitin. Total measurement time for two spectra was $\sim 9$ min with 8 scans each. Peaks shown in blue in figure $(\mathbf{a}, \mathbf{b})$ correspond to $\Omega\left({ }^{15} \mathrm{~N}_{i+1}+\mathrm{K}{ }^{*}{ }^{13} \mathrm{C}^{\prime}{ }_{i+1}\right)$ and $\Omega\left({ }^{15} \mathrm{~N}_{i+1}-\mathrm{K}{ }^{* 13} \mathrm{C}_{i+1}^{\prime}\right)$, respectively. The scaling factor $\mathrm{k}$ was set to 0.5 . The NUS time increments in the shared dimension which was actually acquired in the experiment are shown in blue bars; (c,d), represents the overlay of $1 \mathrm{D}$ projection of linearly acquired data (cyan) and non-uniformly acquired data (blue) along $\omega_{1}$ for $\Omega\left({ }^{15} N_{i+1}+k{ }^{* 13} C^{\prime}{ }_{i+1}\right)$ and $\Omega\left({ }^{15} N_{i+1}-k{ }^{* 13} C^{\prime}{ }_{i+1}\right)$ respectively. There is $27 \%$ reduction in signal to noise ratio ongoing from linearly acquired data to NUS data as measured by the SNR of the projections.

\section{Discussion}

Amino acid selective unlabeling has been shown to be a robust, easy and cost-effective method for simplifying NMR spectrum and obtaining useful structural information in proteins $[11,15,27-30]$. On the other hand, GFT NMR is a powerful technique for speeding up NMR data acquisition and has been shown to be useful in various applications [2,18,19,31-46]. In the present study, the application of two fast NMR methods, namely GFT NMR and non-uniform sampling to selectively unlabeled protein samples expands the repertoire of applications possible with selective unlabeling. In our previous 
study, we reported an experiment for identification of $\left[{ }^{15} \mathrm{~N}_{i+1},{ }^{1} \mathrm{H}_{i+1}\right]$ shifts based on a $2 \mathrm{D}{ }^{12} \mathrm{CO}$-filtered $\left[{ }^{15} \mathrm{~N},{ }^{1} \mathrm{H}\right] \mathrm{HSQC}$. The new experiment proposed herein, namely, 2D HN(CA) $(i+1)$ improves upon the selection of unlabeled $(i)$-labeled $(i+1)$ pair by incorporating two filters simultaneously. That is, attenuating the ${ }^{15} \mathrm{~N}_{i+1}$ magnetization by allowing its scalar coupling to both ${ }^{13} \mathrm{CO}_{i}$ and ${ }^{13} \mathrm{C}^{\alpha}{ }_{i}$. The delay periods used in the r.f. pulse sequences are appropriately tuned to achieve the desired selection. The only limitation of the approach is the additional sample requirement. Additionally, not all the amino acids can be used for unlabeling as cross metabolism is an issue. However, we have extensively studied on the cross metabolism issue and came up with excellent solutions of many different combinations of amino acids which can be used as starting point. These combinations greatly cover a large percentage of residues in the sequences and the resonance assignment strategies can be simplified to a large extent. Considering the cost-effective solution this approach is much better than selective labeling as the cross metabolism is also an issue there.

Having thus achieved a selection of $\left[{ }^{15} \mathrm{~N}_{i+1},{ }^{1} \mathrm{H}_{i+1}\right]$ resonances, the application of GFT NMR and NUS methodology helps to provide high dimensional spectral information, namely ${ }^{13} \mathrm{C}^{\alpha}{ }_{i+1}$, ${ }^{13} \mathrm{C}^{\beta}{ }_{i+1}$ and ${ }^{13} \mathrm{CO}_{i+1}$ correlations, rapidly. The two $(3,2) \mathrm{D}$ GFT experiments proposed thus augment the conventional assignment strategy involving $3 \mathrm{D}$ HNCACB and $3 \mathrm{D} C B C A(\mathrm{CO}) \mathrm{NH}$ without severely increasing the overall measurement time. Further, the information obtained can be used for automated resonance assignment strategies to speed up data analysis. Since the experiments are based on the "HNCA" based approach, the methodology can be extended in a straightforward manner to detect ${ }^{1} \mathrm{H}^{\alpha}$ or measure scalar/dipolar couplings, which involve HNCA type editing.

\section{Materials and Methods}

\subsection{Sample Preparation}

The plasmid (PGLUB $)$ coding for ubiquitin was transformed into E. coli BL21 cells (New England Biolabs, Ipswich, MA, USA). Cells were grown at $37^{\circ} \mathrm{C}$ in M9 medium containing $1 \mathrm{~g} / \mathrm{L}$ of ${ }^{15} \mathrm{NH}_{4} \mathrm{Cl}$ (Cambridge Isotope Laboratories, Tewksbury, MA, USA) and $4 \mathrm{~g} / \mathrm{L}$ of ${ }^{13} \mathrm{C}$-Glucose (Cambridge Isotope Laboratories, Tewksbury, MA, USA). For selective unlabeling, $1.0 \mathrm{~g} / \mathrm{L}$ each of desired unlabeled amino acid(s): Arg and Asn (stock solution of $1.0 \mathrm{~g}$ in $50 \mathrm{~mL}$ of $\mathrm{H}_{2} \mathrm{O}$ was prepared and filter sterilized) was added to the growth medium. To induce protein expression, $1.0 \mathrm{mM}$ isopropyl $\beta$-D-thiogalactoside (IPTG) (Sigma-Aldrich, St. Louis, MO, USA) was added at midlog phase (O.D $600 \sim 0.6)$. Cells were harvested by centrifugation and suspended in acetate buffer ( $5 \mathrm{mM}$ EDTA (Sigma-Aldrich, St. Louis, MO, USA), $50 \mathrm{mM}$ Na acetate (Sigma-Aldrich, St. Louis, MO, USA), pH 5) and taken up for sonication. Following sonication, the supernatant containing the protein was loaded on to a pre-equilibrated ion exchange column (SP Sepharose fast flow from GE) and the protein eluted with a salt gradient of 0-0.6 M NaCl. The protein sample was further purified using size-exclusion chromatography with Superdex 75 (Sigma-Aldrich, St. Louis, MO, USA). For NMR data acquisition, a sample containing $\sim 1.0 \mathrm{mM}$ of protein in $50 \mathrm{mM}$ phosphate buffer $\left(10 \%{ }^{2} \mathrm{H}_{2} \mathrm{O}, \mathrm{pH} 6.0\right)$ was prepared.

\subsection{NMR Data Collection}

All NMR data were acquired at $298 \mathrm{~K}$ on a Bruker Avance $800 \mathrm{MHz}$ NMR spectrometer (Billerica, MA, USA) equipped with a room temperature triple resonance probe with a $\mathrm{z}$-axis shielded gradient. Data were processed with NMRPipe [47] and analyzed using XEASY [48].

\section{Conclusions}

Three new NMR experiments are presented which are applicable to protein samples prepared with amino acid selective unlabeling. The experiments provide ${ }^{15} \mathrm{~N},{ }^{1} \mathrm{HN},{ }^{13} \mathrm{C}^{\alpha},{ }^{13} \mathrm{C}^{\beta},{ }^{13} \mathrm{C}^{\prime}$ chemical shifts for amino acid residues which are immediate C-terminal neighbors $(i+1)$ of selectively unlabeled residues. Two of the experiments provide 3D shift correlations rapidly using the methodology of GFT NMR and non-uniform sampling. The data acquisition time can be further reduced using 
the method of longitudinal ${ }^{1} \mathrm{H}$ relaxation optimization [19]. The spectral simplification obtained combined with rapid data collection will help in reducing the time required for data analysis. In addition to resonance assignments, the proposed methodology can also be used for studies such as protein-ligand and protein-protein interactions, which involve monitoring the changes in shifts of certain residues against a background of unshifted resonances. Taken together, the proposed methodology expands the repertoire of applications possible with amino acid selective unlabeling for rapid protein structural studies.

Acknowledgments: The facilities provided by NMR Research Centre at IISc supported by Department of Science and Technology (DST), India is gratefully acknowledged. K.C. acknowledges support from DST Inspire Faculty Scheme (IFA 13-CH 106). H.S.A. acknowledges support from DBT and DAE-BRNS research awards.

Author Contributions: H.S.A. and K.C. conceived and designed the experiments; B.K. and K.C. performed the experiments and analyzed the data; B.K., K.C. and H.S.A. wrote the paper.

Conflicts of Interest: The authors declare no conflict of interest.

\section{References}

1. Atreya, H.S.; Szyperski, T. Rapid NMR data collection. Methods Enzymol. 2005, 394, 78-108. [PubMed]

2. Szyperski, T.; Atreya, H.S. Principles and applications of GFT projection NMR spectroscopy. Magn. Reson. Chem. 2006, 44, S51-S60. [CrossRef] [PubMed]

3. Schanda, P. Fast-pulsing longitudinal relaxation optimized techniques: Enriching the toolbox of fast biomolecular NMR spectroscopy. Prog. NMR Spectrosc. 2009, 55, 238-265. [CrossRef]

4. Felli, I.C.; Brutscher, B. Recent Advances in Solution NMR: Fast Methods and Heteronuclear Direct Detection. ChemPhysChem 2009, 10, 1356-1368. [CrossRef] [PubMed]

5. Cavanagh, J.; Fairbrother, W.J.; Palmer, A.G.; Skelton, N.J. Protein NMR Spectroscopy; Academic Press: San Diego, CA, USA, 1996.

6. Pudakalakatti, S.; Chandra, K.; Thirupathi, R.; Atreya, H.S. Rapid Characterization of Molecular Diffusion by NMR. Chem. Eur. J. 2014, 20, 15719-15722. [CrossRef] [PubMed]

7. Mulleti, S.; Singh, A.; Brahmkhatri, V.P.; Chandra, K.; Raza, T.; Mukherjee, S.P.; Seelamantula, C.S.; Atreya, H.S. Super-resolved nuclear magnetic resonance spectroscopy. Sci. Rep. 2017, 7, 9651.

8. Khaneja, N.; Dubey, A.; Atreya, H.S. Ultra broadband NMR spectroscopy using multiple rotating frame technique. J. Magn. Reson. 2016, 265 (Suppl. C), 117-128. [CrossRef] [PubMed]

9. Atreya, H.S. Isotope labeling in Biomolecular NMR. In Advances in Experimental Medicine and Biology; Springer: Amsterdam, The Netherlands, 2012; pp. 1-219.

10. Krishnarjuna, B.; Jaipuria, G.; Thakur, A.; D'Silva, P.; Atreya, H.S. Amino acid selective unlabeling for sequence specific resonance assignments in proteins. J. Biomol. NMR 2011, 49, 39-51. [CrossRef] [PubMed]

11. Prasanna, C.; Dubey, A.; Atreya, H.S. Amino acid selective unlabeling in protein nmr spectroscopy. In Methods in Enzymology; Kelman, Z., Ed.; Academic Press: Cambridge, MA, USA, 2015; pp. 167-189.

12. Vuister, G.W.; Kim, S.J.; Wu, C.; Bax, A. 2D and 3D NMR-Study of Phenylalanine Residues in Proteins by Reverse Isotopic Labeling. J. Am. Chem. Soc. 1994, 116, 9206-9210. [CrossRef]

13. Shortle, D. Assignment of amino acid type in ${ }^{1} \mathrm{H}_{-}{ }^{15} \mathrm{~N}$ correlation spectra by labeling with ${ }^{14} \mathrm{~N}$-amino acids. J. Magn. Reson. 1994, 105, 88-90. [CrossRef]

14. Atreya, H.S.; Chary, K.V.R. Amino acid selective 'unlabelling' for residue-specific NMR assignments in proteins. Curr. Sci. 2000, 79, 504-507.

15. Atreya, H.S.; Chary, K.V.R. Selective 'unlabeling' of amino acids in fractionally ${ }^{13} \mathrm{C}$ labeled proteins: An approach for stereospecific NMR assignments of $\mathrm{CH}_{3}$ groups in Val and Leu residues. J. Biomol. NMR 2001, 19, 267-272. [CrossRef] [PubMed]

16. Dubey, A.; Kadumuri, R.V.; Jaipuria, G.; Vadrevu, R.; Atreya, H.S. Rapid NMR assignments of proteins by using optimized combinatorial selective unlabeling. ChemBioChem 2016, 17, 334-340. [CrossRef] [PubMed]

17. Kim, S.; Szyperski, T. GFT NMR, a new approach to rapidly obtain precise high-dimensional NMR spectral information. J. Am. Chem. Soc. 2003, 125, 1385-1393. [CrossRef] [PubMed]

18. Atreya, H.S.; Szyperski, T. G-matrix Fourier transform NMR spectroscopy for complete protein resonance assignment. Proc. Natl. Acad. Sci. USA 2004, 101, 9642-9647. [CrossRef] [PubMed] 
19. Orekhov, V.Y.; Ibraghimov, I.V.; Billeter, M. MUNIN: A new approach to multi-dimensional NMR spectra interpretation. J. Biomol. NMR 2001, 20, 49-60. [CrossRef] [PubMed]

20. Orekhov, V.Y.; Ibraghimov, I.; Billeter, M. Optimizing resolution in multidimensional NMR by three-way decomposition. J. Biomol. NMR 2003, 27, 165-173. [CrossRef] [PubMed]

21. Rovnyak, D.; Frueh, D.P.; Sastry, M.; Sun, Z.Y.J.; Stern, A.S.; Hoch, J.C.; Wagner, G. Accelerated acquisition of high resolution triple-resonance spectra using non-uniform sampling and maximum entropy reconstruction. J. Magn. Reson. 2004, 170, 15-21. [CrossRef] [PubMed]

22. Hoch, J.C.; Stern, A.S. Maximum entropy reconstruction, spectrum analysis and deconvolution in multidimensional nuclear magnetic resonance. In Nuclear Magnetic Resonance of Biologica Macromolecules; Academic Press: Cambridge, MA, USA, 2001; Part A, pp. 159-178.

23. Hoch, J.C.; Maciejewski, M.W.; Filipovic, B. Randomization improves sparse sampling in multidimensional NMR. J. Magn. Reson. 2008, 193, 317-320. [CrossRef] [PubMed]

24. Jaravine, V.A.; Orekhov, V.Y. Targeted acquisition for real-time NMR spectroscopy. J. Am. Chem. Soc. 2006, 128, 13421-13426. [CrossRef] [PubMed]

25. Tugarinov, V.; Kay, L.E.; Ibraghimov, I.; Orekhov, V.Y. High-resolution four-dimensional H-1-C-13 NOE spectroscopy using methyl-TROSY, sparse data acquisition, and multidimensional decomposition. J. Am. Chem. Soc. 2005, 127, 2767-2775. [CrossRef] [PubMed]

26. Rasia, R.M.; Brutscher, B.; Plevin, M.J. Selective isotopic unlabeling of proteins using metabolic precursors: Application to NMR assignment of intrinsically disordered proteins. ChemBioChem 2012, 13, 732-739. [CrossRef] [PubMed]

27. Kelly, M.J.S.; Krieger, C.; Ball, L.J.; Yu, Y.; Richter, G.; Schmieder, P.; Bacher, A.; Oschkinat, H. Application of amino acid type-specific $1 \mathrm{H}$ and $14 \mathrm{~N}$ labeling in a $2 \mathrm{H}-, 15 \mathrm{~N}$-labeled background to a $47 \mathrm{kDa}$ homodimer: Potential for NMR structure determination of large proteins. J. Biomol. NMR 1999, 14, 79-83. [CrossRef] [PubMed]

28. Mohan, P.M.K.; Barve, M.A.; Chatteljee, A.; Ghosh-Roy, R.V. Hosur, NMR comparison of the native energy landscapes of DLC8 dimer and monomer. Biophys. Chem. 2008, 134, 10-19. [CrossRef] [PubMed]

29. Tugarinov, V.; Kay, L.E. Stereospecific NMR assignments of prochiral methyls, rotameric states and dynamics of valine residues in malate synthase G. J. Am. Chem. Soc. 2004, 126, 9827-9836. [CrossRef] [PubMed]

30. Mukherjee, S.; Mustafi, S.M.; Atreya, H.S.; Chary, K.V.R. Measurement of ${ }^{1} J\left(\mathrm{~N}_{i}, \mathrm{C}^{\alpha}{ }_{i}\right),{ }^{1} J\left(\mathrm{~N}_{i}, \mathrm{C}^{\prime}{ }_{i-1}\right)$, ${ }^{2} J\left(\mathrm{~N}_{i}, \mathrm{C}^{\alpha}{ }_{i-1}\right),{ }^{2} J\left(\mathrm{H}^{N}{ }_{i}, \mathrm{C}^{\prime}{ }_{i-1}\right)$ and ${ }^{2} J\left(\mathrm{H}^{N}{ }_{i}, \mathrm{C}^{\alpha}{ }_{i}\right)$ values in ${ }^{13} \mathrm{C} /{ }^{15} \mathrm{~N}$-labeled proteins. Magn. Reson. Chem. 2005, 43, 326-329. [CrossRef] [PubMed]

31. Rout, M.; Mishra, P.; Atreya, H.S.; Hosur, R.V. Reduced dimensionality 3D HNCAN for unambiguous HN, CA and N assignments in proteins. J. Magn. Reson. 2012, 216, 161-168. [CrossRef] [PubMed]

32. Chandra, K.; Jaipuria, G.; Shet, D.; Atreya, H.S. Efficient sequential assignments in proteins with reduced dimensionality ${ }_{3} \mathrm{D} \underline{\mathrm{HN}}(\mathrm{CA}) \mathrm{NH}$. J. Biomol. NMR 2011, 52, 115-126. [CrossRef] [PubMed]

33. Franks, W.T.; Atreya, H.S.; Szyperski, T.; Rienstra, C.M. GFT projection NMR spectroscopy for proteins in the solid state. J. Biomol. NMR 2010, 48, 213-223. [CrossRef] [PubMed]

34. Jaipuria, G.; Thakur, A.; D'Silva, P.; Atreya, H.S. High-resolution methyl edited GFT NMR experiments for protein resonance assignments and structure determination. J. Biomol. NMR 2010, 48, 137-145. [CrossRef] [PubMed]

35. Swain, M.; Atreya, H.S. CSSI-PRO: A method for secondary structure type editing, assignment and estimation in proteins using linear combination of backbone chemical shifts. J. Biomol. NMR 2009, 44, 185-194. [CrossRef] [PubMed]

36. Barnwal, R.P.; Atreya, H.S.; Chary, K.V.R. Chemical shift based editing of $\mathrm{CH}_{3}$ groups in fractionally C-13-labelled proteins using GFT $(3,2)$ D CT-HCCH-COSY: Stereospecific assignments of $\mathrm{CH}_{3}$ groups of Val and Leu residues. J. Biomol. NMR 2008, 42, 149-154. [CrossRef] [PubMed]

37. Barnwal, R.P.; Rout, A.K.; Atreya, H.S.; Chary, K.V.R. Identification of C-terminal neighbours of amino acid residues without an aliphatic C-13(gamma) supercript stop as an aid to NMR assignments in proteins. J. Biomol. NMR 2008, 41, 191-197. [CrossRef] [PubMed]

38. Barnwal, R.P.; Rout, A.K.; Chary, K.V.R.; Atreya, H.S. Rapid measurement of pseudocontact shifts in paramagnetic proteins by GFT NMR spectroscopy. Open Magn. Reson. J. 2008, 1, 16-28. [CrossRef] 
39. Zhang, Q.; Atreya, H.S.; Kamen, D.E.; Girvin, M.E.; Szyperski, T. GFT projection NMR based resonance assignment of membrane proteins: Application to subunit c of $E$. coli $\mathrm{F}_{1} \mathrm{~F}_{0}$ ATP synthase in LPPG micelles. J. Biomol. NMR 2008, 40, 157-163. [CrossRef] [PubMed]

40. Atreya, H.S.; Garcia, E.; Shen, Y.; Szyperski, T. J-GFT NMR for precise measurement of mutually correlated nuclear spin-spin couplings. J. Am. Chem. Soc. 2007, 129, 680-692. [CrossRef] [PubMed]

41. Barnwal, R.P.; Rout, A.K.; Chary, K.V.R.; Atreya, H.S. Rapid measurement of ${ }^{3} \mathrm{~J}\left(\mathrm{H}^{\mathrm{N}}-\mathrm{H}^{\alpha}\right)$ and ${ }^{3} \mathrm{~J}\left(\mathrm{~N}-\mathrm{H}^{\beta}\right)$ coupling constants in polypeptides. J. Biomol. NMR 2007, 39, 259-263. [CrossRef] [PubMed]

42. Atreya, H.S.; Eletsky, A.; Szyperski, T. Resonance assignment of proteins with high shift degeneracy based on 5D spectral information encoded in $\mathrm{G}^{2}$ FT NMR experiments. J. Am. Chem. Soc. 2005, 127, 4554-4555. [CrossRef] [PubMed]

43. Eletsky, A.; Atreya, H.S.; Liu, G.H.; Szyperski, T. Probing structure and functional dynamics of (large) proteins with aromatic rings: L-GFT-TROSY (4,3)D HCCHNMR spectroscopy. J. Am. Chem. Soc. 2005, 127, 14578-14579. [CrossRef] [PubMed]

44. Liu, G.H.; Aramini, J.; Atreya, H.S.; Eletsky, A.; Xiao, R.; Acton, T.; Ma, L.C.; Montelione, G.T.; Szyperski, T. GFT NMR based resonance assignment for the 21 kDa human protein UFC1. J. Biomol. NMR 2005, 32, 261. [CrossRef] [PubMed]

45. Liu, G.H.; Shen, Y.; Atreya, H.S.; Parish, D.; Shao, Y.; Sukumaran, D.K.; Xiao, R.; Yee, A.; Lemak, A.; Bhattacharya, A.; et al. NMR data collection and analysis protocol for high-throughput protein structure determination. Proc. Natl. Acad. Sci. USA 2005, 102, 10487-10492. [CrossRef] [PubMed]

46. Shen, Y.; Atreya, H.S.; Liu, G.H.; Szyperski, T. G-matrix Fourier transform NOESY-based protocol for high-quality protein structure determination. J. Am. Chem. Soc. 2005, 127, 9085-9099. [CrossRef] [PubMed]

47. Delaglio, F.; Grzesiek, S.; Vuister, G.W.; Zhu, G.; Pfeifer, J.; Bax, A. NMRpipe-A Multidimensional Spectral Processing System Based on Unix Pipes. J. Biomol. NMR 1995, 6, 277-293. [CrossRef] [PubMed]

48. Bartels, C.; Xia, T.H.; Billeter, M.; Güntert, P.; Wüthrich, K. The Program Xeasy for Computer-Supported NMR Spectral-Analysis of Biological Macromolecules. J. Biomol. NMR 1995, 6, 1-10. [CrossRef] [PubMed]

(C) 2017 by the authors. Licensee MDPI, Basel, Switzerland. This article is an open access article distributed under the terms and conditions of the Creative Commons Attribution (CC BY) license (http:/ / creativecommons.org/licenses/by/4.0/). 